\title{
On the Relationship among User's Reading Behavior, Algorithm Recommendation Mechanism and the Manufactured Filter Bubbles Effect
}

\author{
Yun Zhao ${ }^{1}$, Tianyi Zhou ${ }^{1}$, Yunqian Zhou* \\ ${ }^{1}$ School of Journalism and Communication, Nanchang University, Nanchang Jiangxi, China \\ *Corresponding Author.
}

\begin{abstract}
This paper analyses the causal logic of algorithm recommendation and it employs the Pielou index to measure the distribution of news contents to provide empirical evidence to indicate whether the algorithm recommendation mechanism may produce filter bubbles. Moreover, this research takes Headlines Today as the research object to better understand the realization of tailored news and how their reading behaviour affect the algorithm recommendation mechanism. Meanwhile, the conclusion reinforces that users should enhance their information literacy in the era of artificial intelligence and big data, make rational use of algorithm recommendation mechanism, and pay close attention to the diversity of information sources to avoid information bias. This paper also helps the information flow platform to reflect on the shortcomings of the algorithm mechanism and optimise its strengths while avoiding those manufactured negative effects and proposes that in the optimisation of algorithm recommendation mechanism, the positive guidance to users should also be emphasised. Indicators such as content influence and mainstream media recommendation can be added to generate a multi-index recommendation.
\end{abstract}

Keywords: user's reading behaviour, algorithm recommendation mechanism, the manufactured filter bubbles effect, generate content diversity

\section{Introduction}

The algorithm recommendation mechanism is widely recognised since it plays an increasingly influential role in media consumption [1]. According to the data released by Analysis of Netizens' Behavior 2016, in China's information market, the algorithm recommendation share has exceeded the manual push share [2]. Reuters Institute Digital News Report 2017 states that compared with reporters or editors' choosing news information for readers, $54 \%$ of respondents prefer to use algorithmic recommendations for daily new consumption, and such trend is more prominent among the youth, with the rate as high as 64\%. Digital News Report 2020 also reinforces greater reliance on social media and other platforms for personalised news reading.

Algorithm recommendation mechanism, as a kind of intelligent remediation distribution method, based on users' interests map, undoubtedly improves the effectiveness and accuracy of news personalisation. Scholars also have raised concerns as to whether algorithms bring about filter bubbles [3]. As Pariser suggests that it cannot guarantee diversity while focusing on maximising economic profits by increasing media consumption [4]. The users are isolated from other diversified information. Their reading behaviours are gradually confined to the homogeneous filter bubbles, so it is difficult to break through barriers to locate new items.

The present study empirically tests this rationale for the case of the news aggregator Headlines Today. This article is composed of four main parts. First, it starts with the evolving roles and functions that algorithms and algorithm recommendation mechanism serve in the dynamics of contemporary media production and consumption and the filter bubbles effect on users' consumption behaviours. Second, it details the participants, the method of quantitative experimental research, and the data analysis process. Then, it unfolds the empirical findings of the relationship among users' reading behaviour, the algorithmic recommendation system and the filtering bubble. The concluding section considers both the practical and research implications of this empirical approach of algorithm

ISSN: 0010-8189

(C) CONVERTER 2020

www.converter-magazine.info 
recommendation and also detects the future trends of recommendation design.

\section{Literature review and research questions}

\subsection{Headlines Today}

Headlines Today, with the slogan "Your interest is the headline", has stood out in just a few years and become the largest news aggregation platform in China. Now Headlines Today occupies the biggest market shares and enjoys the highest popularity in China. Its appearance and development have brought great changes to news dissemination. Such a convenient, instant reading style, with abundant contents and a strong social interaction mechanism, has won the favour of the majority of Chinese netizens. It has changed the legacy media, in which journalists and editors used to work as gatekeepers. However, heated discussions are also held concerning its news characteristics, contents piracy and negative effects among all walks of life. A plethora of researches have been conducted with Headlines Today, mainly focusing on the following three perspectives.

To explore the news characteristics of Headlines Today. From the perspective of product characteristics, Xia sums up three tips for the success of Headlines Today: the customised recommendation list based on users' interests, a wealth of high-quality contents, promotions of users' interaction through social reading [5]. Xu points out that, compared with the legacy media, the algorithm recommendation mechanism has unique advantages to produce news, such as humanised backstage editing, quick recommendation process, simple and easy-to-use interface [6].These characteristics further promote users to rely on browsing and sharing news on the aggregator. Cai believes that the competitive advantages of Headlines Today mainly rely on its personalisation, aggregation, easy operation and instant update, and these factors contribute to the harmonious win-win cooperation between users and the aggregator [7]. Wang believes that the key to the success of Headlines Today is its mature and complete algorithm recommendation technology that gives full play to the users, and meet the diversified information needs of users while it is impossible to be handled by the legacy media [8].

To clarify the piracy of Headlines Today. In the year 2014, several media institutions accused Headlines Today of tort their news contents, which triggered an academic discussion on whether the Internet-based information distribution and recommendation model conforms to the media communication standard and violates the Copyright Law. Zhang argues that the aggregation platform, as such Headlines Today, makes deep links to other news websites without authorisation, which is an infringement, and thus the aggregator needs to bear tort liability [9]. Wang holds that the deep-chain technology applied by Headlines Today does not violate Copyright Law itself, but if it is not set properly, it will result in unfair competition [10]. The media organisations have paid high costs to produce high-quality contents while obtaining no corresponding profits. However, it has been deprived by Headlines Today through reselling of advertising, since the aggregator has adopted those high-quality contents to improve its news quality, users' stickiness and its social influence. Wei maintains that how Headlines Today disseminate news is similar as scratching the edge and therefore he puts forward the following regulatory suggestions: Internet companies should improve their operating systems, and law enforcement departments should stop and even adopts sanction of their infringements while the legacy media should cooperate with the news aggregators, taking full advantage of their platform to create win-win cooperation among the legacy media, the new media and users [11]. Yu holds that in order to solve the copyright dispute of Headlines Today thoroughly, the focus should be put on the issue of profits sharing between legacy media and the Internet companies instead of the news business [12].

To survey the negative effect of Headlines Today. Mei believes that the characteristics of rapidity and convenience have contributed to the success of Headlines Today, but also brought about a large number of sensational headlines and fake news [13]. Zhao sums the phenomenon of information cocoons of Headlines Today as the narrowing of users' horizon, the reduction of individuals' ability to identify information, as well as the lack of social stickiness and intensified group polarisation [14]. Shao holds that Headlines Today aggregates the various news resources and distributes all diversified news to specific users through an algorithm recommendation mechanism, which subverts the traditional working process of legacy media like writing, editing, reviewing and issuing by reporters

ISSN: 0010-8189

(C) CONVERTER 2020 
[15]. Such a mechanism, on one the hand, improves the efficiency of news distribution but, on the other hand, lowers the media ethics, such as the problem of copyright protection and the boom of poor-quality news. Zhou believes that the personalised algorithm of Headlines Today recommends the most tailored news according to the spontaneous needs of users, which best meets users' news consumption interests and demands, but also makes them live in a closed news loop [16].

\subsection{The algorithm recommendation mechanism}

With the rapid development of algorithm recommendation mechanism, it has been widely used in social media, news recommendation, book recommendation, online shopping and other fields. The algorithm recommendation mechanism can filter information from massive data and meet the various information needs of different users through specific algorithms and technologies. An increasing number of researches have been conducted concerning the algorithm recommendation mechanism from the following three perspectives.

To map the development of the algorithmic recommendation system and conduct theoretical research to list the latest research progress and research directions. Liu systematically reviews the research progress of the then recommendation system from the aspects of users' information collecting and modelling, personalised algorithm recommendation, its evaluation and application, and lists the future hot topics of recommendation system research [17]. Liu introduces different accuracy metrics and their advantages and disadvantages of different tasks of the algorithm recommendation mechanism and their defects of the current evaluation index, and the possible improvement direction in the future [18]. Wang expounds on the key technologies of recommendation mechanism with three modules: user modelling, recommendation object modelling and recommendation strategy, and also summarises the performance evaluation indexes of recommendation algorithms [19].

To conduct individual case studies of the algorithmic recommendation system. Four major algorithms are classified as a content-based recommendation, collaborative filtering recommendation, model-based recommendation, and hybrid recommendation system. Li puts forward a new recommendation model, integrating the advantages of the two recommendation systems while avoiding their shortcomings, which effectively improves the accuracy of recommendation [20]. Hu proposes a hybrid collaborative filtering algorithm recommendation based on deep learning, and their test shows that compared with the traditional algorithm, the new model can effectively improve the validity [21].

To analyse the practical applications of the algorithm recommendation mechanism in the fields of library management, e-commerce, education, games, etc. Liu introduces a combined recommendation algorithm based on user-based collaborative filtering and project-based collaborative filtering in the e-supermarket shopping system [22]. Zeng proposes a personalised information recommendation model for mobile reading based on context awareness. The experimental results show that it can provide personalized mobile reading service for readers in specific situations [23]. Mou promotes a hybrid recommendation design according to learner's personalized characteristic information recorded in various databases of e-schoolbags [24]. Sha proposes a personalized game recommendation based on implicit feedback data and constructs a user recommendation model according to various implicit data of users and experiments show that its accuracy is better than the previous game recommendation mechanism [25].

\subsection{The algorithm recommendation mechanism and filter bubbles}

When the algorithm recommendation mechanism is employed in news recommendation, news distribution, news curation and other related journalism and communication fields, it becomes the technological basis to provide customers with personalised news service. It has already existed as the dominant news source. On one hand people appreciate the wonderfulness of algorithmic news. On the other hand, people also raise curiosities concerning the filter bubbles effect brought by it. Several researches have been done from the following three aspects.

To emphasise the causes and ethical risks of the filter bubble effect. Jiang believes that with the emergence of algorithmic news, users are increasingly involved in the information cocoon room, which has caused community ISSN: 0010-8189 
polarisation [26]. Zhao argues that excessive dependence on algorithmic technology will cause a series of ethical risks such as cognitive bias, alienation of values, lack of publicity, algorithmic bias and discrimination [27]. Zhang distinguishes two main causes of the filter bubble effects: the defect of big data technology and the absence of a news regulation mechanism [28]. Hu believes that artificial intelligence has a great impact on media ecology, especially in news production and distribution and with the continuous development of artificial intelligence, the future media ecology will face more new challenges [29]. Hu holds that with the rapid development of modern technology, news algorithm technology has become increasingly prominent in violation of ethics, leading to privacy violations, moral transgressions, value misplacement and other issues [30]. Yang regards Internet companies as the gatekeepers of news information, replacing the legacy media with the flourishing of personalised recommendation algorithm, which will lead to a series of problems of communication ethics anomie such as the community polarisation, community isolation and value differentiation brought by the continuous deepening of the filter bubbles effect [31]. Guo believes that due to the dislocations of value rationality and technical rationality, the algorithm recommendation mechanism has brought a great impact on traditional news values in the process of news production and distribution, which has caused a list of crisis like alienation of audience values and the lost control of public opinion [32].

To study the transparency of the algorithm and the regulation of the filter bubble effect. Wang adopts quantitative research of the use of Headlines Today and finds four major concepts of its algorithmic value, that is, scene, content, users' preferences and platform priorities [33]. Xu holds that heterogeneous factors have been integrated into the algorithmic programming at the beginning of its design, for example, the commercial interests of the aggregator and the content construction scheme [34]. Therefore, the algorithm recommendation mechanism does not exist as a solid concept, nor a pure technology, but as ambiguous and flowing. Fang explains the algorithmic recommendation system from three perspectives: the core algorithm of news recommendation, the weight of news elements and the algorithm of news by combing the patent statements of Facebook and Google, public comments and news reports on the Internet, therefore, it is concluded that the core design of the algorithmic recommendation system should be user-oriented [35]. Then to regulate the filter bubble effects, Guo argues that the filter bubbles effect is the result of the joint action of technology, humanity and social structure, so its elimination requires not only the optimization of technology, the balanced coverage of media, but also the alleviation of social contradictions and the improvement of deliberative negotiation mechanism [36].

To discuss the value of the filter bubbles effect. Chen believes that the structural defects of algorithm recommendation and the bias of input data determine its ethical defects, which are difficult to be bridged by technical means [37]. Because of the operating mechanism, it is easy to generate information cocoons, so humanistic values are applied to correct the algorithm values. What's more, since the algorithm mechanism is written by algorithmic engineers, bearing the imprint of human social values by nature, it is impossible to consider it neutral. Zhang advocate that in the era of big data, technology is becoming more and more instrumentally rational, so economic interests and business efficiency are put in the most important position prior to humanistic care, which causes serious emergencies of social problems [38].

Does the algorithm recommendation mechanism cause the filter bubbles effect? There are great disputes among scholars. Resnick proposes that the recommendation mechanism of social media would aggravate the filter bubble effect and increase inter-group prejudice [39]. Through comparative experiments, Nguyen also finds that if users receive news through the recommendation system, they have to encounter reduced content diversity. In the long run, the degree of reduced content diversity is more significant than that of groups that do not receive recommended content [40]. Bechmann analyses the similarity between the external links shared by 1,000 Facebook users and the published content, and finds that less than $10 \%$ of the participants were caught in the filter bubble effect of Facebook [41]. According to the conclusions of two exploratory studies by Haim, it is found that besides the slight impact of implicit personalisation on content diversity, the filter bubbles effect caused by the algorithm is undoubtedly exaggerated [42]. After comparing the recommendation data output by different algorithms with the recommendation data output by manual editing in the same news database, Möller finds that the algorithm recommendation mechanism does not reduce diversity, but improves it [43].

ISSN: 0010-8189

(C) CONVERTER 2020

www.converter-magazine.info 
To sum up, a plethora of researches have been conducted concerning the theoretical analysis on the algorithm recommendation mechanism and the filter bubbles effect, and full emphasis has been put on the quantitative studies of international aggregators such as Facebook, etc. Headlines Today, as the most prominent aggregator in China, there is obviously a lack of quantitative research. Considering all these, it is meaningful to testify whether the recommendation mechanism of Headlines Today causes the filter bubbles effect through verifying the increase/decrease of content diversity.

\subsection{Research questions}

Based on the above literature review, taking users' behaviour as the variable, three research questions are designed to investigate whether the algorithm recommendation mechanism will cause the filter bubbles effect with the increase or decrease of diversity, and meanwhile to verify the causal process among users' behaviours, the algorithm recommendation mechanism and the filter bubbles.

- Research Question 1 (RQ1): Is there a positive correlation between users' reading behaviour and the algorithm recommendation mechanism?

- Research Question 2 (RQ2): Dose the aggregator's algorithm recommendation mechanism cause the decrease of content diversity and the filter bubbles effect?

- Research Question 3 (RQ3): Will users' preferred reading behaviour exert an impact on the filter bubbles?

\section{Research method and participants}

The general research idea is to collect and measure the users' reading behavior data (i.e. input) and the aggregator's commendation data (i.e. output), to explore whether the algorithm recommendation mechanism causes the filter bubbles effect and its internal working mechanism.

Several factors, such as user's gender, search history, likes, comments, favourites, etc. all affect the modelling of users' interest map by algorithm recommendation mechanism with users' reading behaviour as the leading tag. Therefore, this study will explore the actual impact of users' historical reading behaviour on algorithm recommendation by recording users' reading data (i.e.input) and comparing the theme category changes of aggregators' recommended data (i.e. output). Considering the above contributing elements, the research is carried out in two groups. The first group is the free reading group, which means that the participants are free to read the contents according to their interests. The other is the controlled reading group, that is, the participants are confined to read only certain types of information. By comparing the similarities and differences of the topic categories received by the two groups members, the recommendation logic of the algorithm mechanism is summarised, and then to evaluate whether the users' reading preferences affect the filter bubbles.

The research also pays attention to whether the algorithm recommendation mechanism reduces the content diversity. According to the operational mechanism of personalized recommendation, the news aggregators usually filter out the content that users are not interested in according to the algorithm mechanism, and only present their interested content. For example, due to the users' limited attention resources, a movie fun or an entertainment craze will be recommended with a large number of movies or entertaining contents recommended by the aggregator at the expense of being less exposed to other categories of content. The research group adopts the Pielou Evenness Index to measure whether the theme categories of recommended content gradually narrows with the forming of users' reading behavior, so as to verify the existence of filter bubbles effects.

ISSN: 0010-8189

(C) CONVERTER 2020 
Several indexes are used to measure content diversity, such as ( $H_{\text {Rao,diversity }}=\sum_{j=1} p_{j} \sum_{i \neq j} d_{i, j} p_{i}$

$$
\left(H_{\text {shannon }}=-\sum p_{i} \log _{b}\left(p_{i}\right)\right) \text { and Simpson's D }\left({ }^{D=1-\sum_{i=1}^{s} p_{i}^{2}}\right) \text { Pielou } J_{s i}=\left(1-\sum P_{i}^{2}\right) /(1-1 / s) \text {. }
$$

Pielou' Evenness Index refers to the distribution of an individual number of all species in a community, and it can reflect the evenness of each individual number distribution. In order to draw an accurate and depictive picture of the concentration of content distribution, our research applies the Pielou index.

\subsection{Research design}

Because the clients' data of aggregator is not open to the public, the team adopts experimental research. Although the total amount of collected data is limited, the research process is highly operable, and all the necessary data are thoroughly stored by manual recording.

3.2 Selection of aggregator

Headlines Today is a popular APP developed by Beijing ByteDance Technology Co., Ltd., one of the most-used news aggregators, which can intelligently recommend personalised information based on the analysis of users' past behaviour. As a pioneer in the news aggregation industry it has received wide attention. With years of development, Headlines Today has been an influential player in this industry, and obtained wide audience coverage, so that it can provide representative data. On the other hand, Headlines Today also possesses the most up-to-date algorithm recommendation mechanism, which can highlight the representativeness of the research samples.

\subsection{Selection of experimental time}

Researchers ever disclosed in detail the operation mechanism of their algorithm recommendation, that is, when the user logs on to the platform, the system will establish a preliminary interests map according to the basic information of the user. Then with the accumulation of users' behaviour data, the interest model established by the system for each user becomes more and more accurate. If users employ Headlines Today six or seven times, the algorithms can accurately judge their reading interest [44].

Therefore, in this study, participants are arranged to take in the reading experiment for ten continuous days. In order to effectively reduce the impact of any unexpected incident on the experimental data, the participants can upload their reading data and aggregator's recommended data from February 3, 2020 to June 1, 2020. iResearch also suggests that the online news consumption time is generally concentrated at working hours, lunch break and before sleeping time, and 18:00-22:00 is the peak time. Therefore, this study requires all participants to store the screenshots of their reading content of the day before 22:30 every day during the 10-day experiment and store the screenshots of the recommended content of Headlines Today before 12:00 the next day.

\subsection{Sample categorisation and coding}

At the end of the experiment, there are 2071 reading items and 3500 recommended items, totaling 5571, are collected. In accordance with the formal Chinese information classification, to highlight important categories and keep balance among them, the items are divided into eight categories: sports/health, finance/science and technology, affairs/social news, education, film and television entertainment, food/car, culture/popular science and life. Within each category the stored items are coded and the Pielou index of individual participant's reading and recommended content are calculated. For example, Table I. shows participant B's data during the 10-day experiment including the algorithmic recommended contents and the corresponding Pielou index.

Table 1 Categories of algorithmic recommended content and its Pielou index (sample figure of Participant B)

ISSN: 0010-8189

(C) CONVERTER 2020 


\begin{tabular}{|c|c|c|c|c|c|c|c|c|c|c|}
\hline A & B & $\mathrm{C}$ & $\mathrm{D}$ & $\mathrm{E}$ & F & G & $\mathrm{H}$ & I & $\mathbf{J}$ & $\mathrm{K}$ \\
\hline $\begin{array}{c}\text { Experi } \\
- \\
\text { ment } \\
\text { days }\end{array}$ & $\begin{array}{c}\text { sports/he } \\
\text { alth }\end{array}$ & $\begin{array}{c}\text { finance/scie } \\
\text { nce } \\
\& \text { technolog } \\
y\end{array}$ & $\begin{array}{l}\text { affairs/so } \\
\text { cial news }\end{array}$ & $\begin{array}{l}\text { educati } \\
\text { on }\end{array}$ & $\begin{array}{l}\text { Film \& } \\
\text { television } \\
\text { entertain } \\
\text { ment }\end{array}$ & $\begin{array}{l}\text { food/ } \\
\text { car }\end{array}$ & $\begin{array}{l}\text { culture/pop } \\
\text { ular } \\
\text { science } \\
\text { and life }\end{array}$ & life & $\begin{array}{l}\text { Freque } \\
\text { ncy }\end{array}$ & $\begin{array}{l}\text { Recommen } \\
\text { ded Pielou } \\
\text { index }\end{array}$ \\
\hline 1 & 1 & 2 & 12 & 0 & 0 & 0 & 9 & 1 & 25 & 0.5776 \\
\hline 2 & 1 & 1 & 11 & 0 & 0 & 0 & 10 & 2 & 25 & 0.5849 \\
\hline 3 & 0 & 0 & 4 & 0 & 0 & 0 & 17 & 4 & 25 & 0.4130 \\
\hline 4 & 1 & 0 & 1 & 0 & 3 & 0 & 15 & 5 & 25 & 0.5227 \\
\hline 5 & 0 & 1 & 3 & 1 & 1 & 0 & 16 & 3 & 25 & 0.4935 \\
\hline 6 & 1 & 1 & 4 & 0 & 0 & 0 & 16 & 3 & 25 & 0.4825 \\
\hline 7 & 1 & 2 & 5 & 0 & 2 & 0 & 12 & 3 & 25 & 0.6581 \\
\hline 8 & 2 & 1 & 9 & 0 & 0 & 0 & 13 & 0 & 25 & 0.5337 \\
\hline 9 & 1 & 2 & 11 & 0 & 0 & 0 & 8 & 3 & 25 & 0.6361 \\
\hline 10 & 2 & 0 & 8 & 1 & 1 & 0 & 12 & 1 & 25 & 0.6069 \\
\hline
\end{tabular}

The calculating formula of the algorithmic recommended contents' Pielou index is as follow:

$$
\begin{aligned}
1-\sum P_{i}^{2} & =1-\left(\left(D_{i} / L_{i}\right)^{2}+\left(E_{i} / L_{i}\right)^{2}+\left(F_{i} / L_{i}\right)^{2}+\left(G_{i} / L_{i}\right)^{2}+\left(H_{i} / L_{i}\right)^{2}+\left(I_{i} / L_{i}\right)^{2}\right. \\
& \left.+\left(J_{i} / L_{i}\right)^{2}+\left(K_{i} / L_{i}\right)^{2}\right)
\end{aligned}
$$

Line $\mathrm{J}$ lists the total amount of recommended contents on that particular day, and the calcutating formula is "=SUM(D2:K2)". Line K lists the recommended contents' Pielou index, and the calculating formula is:

$"=\left(1-\left((D 2 / L 2)^{2}+(E 2 / L 2)^{2}+(F 2 / L 2)^{2}+(G 2 / L 2)^{2}+(H 2 / L 2)^{2}+(I 2 / L 2)^{2}\right.\right.$

$\left.\left.+(J 2 / L 2)^{2}+(K 2 / L 2)^{2}\right) /(1-1 / 8)\right) "$

participants

Based on the Content Consumption Insight Report 2019 by research, of all the respondents there is no big difference between genders, the male occupying 51.2\% and the female 48.3\%. As the educational background, respondents with bachelor's degree, master's degree and $\mathrm{Ph}$. D. s are sharing $83.4 \%, 15.4 \%$ and $1.2 \%$ respectively. Hence, when recruiting participants, the research group selected both male and female, senior and junior, from different locations in order to ensure diverse backgrounds, experiences and perspectives. Fifteen participants are enrolled, but one dropped out during the 10-day experiment because of his sudden broken equipment. Basic information regarding the participants is presented in Table II.

\begin{tabular}{|c|c|c|c|c|c|c|}
\hline $\begin{array}{l}\text { Co } \\
\text { de }\end{array}$ & $\begin{array}{c}\text { Name } \\
\text { Abbreviat } \\
\text { ion }\end{array}$ & $\begin{array}{c}\text { Gend } \\
\text { er }\end{array}$ & Location & Profession & Education & Reading Category \\
\hline \multicolumn{7}{|c|}{ Group One（Free Reading Group） Experimental subjects } \\
\hline A & $\mathrm{ZL}$ & $\begin{array}{c}\text { femal } \\
\mathrm{e}\end{array}$ & $\begin{array}{c}\text { Nanchang,jia } \\
\text { ngxi }\end{array}$ & civil servants & bachelor & free \\
\hline $\mathrm{B}$ & WZJ & male & $\begin{array}{c}\text { Suzhou,jiangs } \\
\mathrm{u}\end{array}$ & $\begin{array}{l}\text { Software } \\
\text { engineer }\end{array}$ & master & free \\
\hline $\mathrm{C}$ & PXY & $\begin{array}{c}\text { femal } \\
\text { e }\end{array}$ & shenzhen & Tourist guide & bachelor & free \\
\hline $\mathrm{D}$ & LJJ & male & $\begin{array}{c}\text { Fuzhou,jiang } \\
\text { xi }\end{array}$ & architect & bachelor & free \\
\hline
\end{tabular}

Table 2 Basic information of the experiment participants

ISSN: 0010-8189

(C) CONVERTER 2020

www.converter-magazine.info 


\begin{tabular}{|c|c|c|c|c|c|c|}
\hline $\mathrm{E}$ & ZTY & male & $\begin{array}{l}\text { Nanchang,jia } \\
\text { ngxi }\end{array}$ & student & master & free \\
\hline $\mathrm{F}$ & FQ & $\begin{array}{c}\text { femal } \\
\mathrm{e}\end{array}$ & $\begin{array}{c}\text { Nanchang,jia } \\
\text { ngxi }\end{array}$ & manager & $\begin{array}{c}\text { junior college } \\
\text { student }\end{array}$ & free \\
\hline G & XZT & male & Fuzhou,fujian & teacher & master & free \\
\hline $\mathrm{H}$ & XTY & $\begin{array}{c}\text { femal } \\
\mathrm{e}\end{array}$ & shanghai & accountant & bachelor & free \\
\hline I & MJZ & male & Fuyang,anhui & $\begin{array}{l}\text { Advertising } \\
\text { planner }\end{array}$ & bachelor & free \\
\hline \multicolumn{7}{|c|}{ Group Two (Control Reading Group) Experimental subjects } \\
\hline $\mathrm{J}$ & HTY & $\begin{array}{c}\text { femal } \\
\mathrm{e}\end{array}$ & $\begin{array}{c}\text { Fuzhou,jiang } \\
\text { xi } \\
\end{array}$ & teacher & bachelor & Culture/popular science \\
\hline K & LJY & $\begin{array}{c}\text { femal } \\
\mathrm{e}\end{array}$ & $\begin{array}{l}\text { Xiangyang,hu } \\
\text { bei }\end{array}$ & journalist & master & $\begin{array}{c}\text { Film \& television } \\
\text { entertainment }\end{array}$ \\
\hline $\mathrm{L}$ & MZR & male & Shanghai & chef & $\begin{array}{c}\text { junior college } \\
\text { student }\end{array}$ & $\begin{array}{c}\text { Gourmet/automobile } \\
\text { category }\end{array}$ \\
\hline M & YYM & $\begin{array}{c}\text { femal } \\
\text { e }\end{array}$ & $\begin{array}{c}\text { Anyang,hena } \\
\mathrm{n}\end{array}$ & Sales assistant & bachelor & Education category \\
\hline $\mathrm{N}$ & ZXL & male & Beijing & Civil servant & bachelor & Finance/Technology \\
\hline
\end{tabular}

The fourteen participants are divided into two groups: one is the free reading group with nine members, and the other is the control reading group with five. All the group members are required to register a new account with Headlines Today and then follow the instructions of research design, i.e. read the contents recommended by Headlines Today and record the data with the specific software Picsew before 12 p.m. every day. Since the screen generally contains five items and considering the limited attention source, only the first 25 are attached importance and required to be shot and stored for later analysis.

\section{Research findings}

4.1 User's reading behaviour significantly affects the content recommendation of the aggregator

After analyzing the data provided by the free reading group, it is found that the user's historical reading behaviour is an important indicator for the aggregator to construct the user's interest map and thus affects the personalised content recommendation. As shown in Table III, of those content categories, among the top 25 items the more users pay attention to, the more they are recommended by the aggregator. Similarly, the less users focus on, and the less likely to be recommended.

Table 3 The proportion of reading and recommended categories of the free reading group

\begin{tabular}{|c|c|c|c|c|c|c|c|c|c|c|}
\hline $\begin{array}{c}\text { Participants } \\
\text { Category }\end{array}$ & & $A$ & B & C & D & $E$ & $\mathrm{~F}$ & G & $\mathrm{H}$ & I \\
\hline \multirow[t]{2}{*}{ sports/health } & $\mathrm{R}$ & $6.17 \%$ & $4.46 \%$ & $\begin{array}{c}9.72 \\
\%\end{array}$ & $\begin{array}{c}7.19 \\
\%\end{array}$ & $\begin{array}{c}3.65 \\
\%\end{array}$ & $4.35 \%$ & $\begin{array}{c}2.55 \\
\%\end{array}$ & $\begin{array}{c}2.03 \\
\%\end{array}$ & $\begin{array}{c}2.96 \\
\%\end{array}$ \\
\hline & $\mathrm{F}$ & $16.00 \%$ & $4.00 \%$ & $\begin{array}{c}7.83 \\
\%\end{array}$ & $\begin{array}{c}7.95 \\
\%\end{array}$ & $\begin{array}{c}4.07 \\
\%\end{array}$ & $4.80 \%$ & $\begin{array}{c}2.40 \\
\%\end{array}$ & $\begin{array}{c}2.13 \\
\%\end{array}$ & $\begin{array}{c}4.11 \\
\%\end{array}$ \\
\hline \multirow{2}{*}{$\begin{array}{c}\text { finance/scien } \\
\text { ce and } \\
\text { technology }\end{array}$} & $\mathrm{R}$ & $6.79 \%$ & $7.01 \%$ & $\begin{array}{c}11.11 \\
\%\end{array}$ & $\begin{array}{c}5.23 \\
\%\end{array}$ & $\begin{array}{c}13.14 \\
\%\end{array}$ & $6.83 \%$ & $\begin{array}{c}6.12 \\
\%\end{array}$ & $\begin{array}{c}4.05 \\
\%\end{array}$ & $\begin{array}{c}5.93 \\
\%\end{array}$ \\
\hline & $\mathrm{F}$ & $8.00 \%$ & $4.00 \%$ & $\begin{array}{c}7.83 \\
\%\end{array}$ & $\begin{array}{c}5.44 \\
\%\end{array}$ & $\begin{array}{c}10.16 \\
\%\end{array}$ & $8.00 \%$ & $\begin{array}{c}6.00 \\
\%\end{array}$ & $\begin{array}{c}5.53 \\
\%\end{array}$ & $\begin{array}{c}6.39 \\
\%\end{array}$ \\
\hline \multirow[t]{2}{*}{$\begin{array}{c}\text { affairs/social } \\
\text { news }\end{array}$} & $\mathrm{R}$ & $30.25 \%$ & $\begin{array}{c}21.66 \\
\%\end{array}$ & $\begin{array}{c}19.44 \\
\%\end{array}$ & $\begin{array}{c}13.73 \\
\%\end{array}$ & $\begin{array}{c}9.49 \\
\%\end{array}$ & $\begin{array}{c}21.74 \\
\%\end{array}$ & $\begin{array}{c}10.71 \\
\%\end{array}$ & $\begin{array}{c}45.95 \\
\%\end{array}$ & $\begin{array}{c}20.74 \\
\%\end{array}$ \\
\hline & $\mathrm{F}$ & $28.00 \%$ & $\begin{array}{c}27.20 \\
\%\end{array}$ & $\begin{array}{c}22.61 \\
\%\end{array}$ & $\begin{array}{c}22.18 \\
\%\end{array}$ & $\begin{array}{c}17.89 \\
\%\end{array}$ & $\begin{array}{c}32.00 \\
\%\end{array}$ & $\begin{array}{c}21.60 \\
\%\end{array}$ & $\begin{array}{c}31.06 \\
\%\end{array}$ & $\begin{array}{c}31.05 \\
\%\end{array}$ \\
\hline
\end{tabular}

ISSN: 0010-8189

(C) CONVERTER 2020 


\begin{tabular}{|c|c|c|c|c|c|c|c|c|c|c|}
\hline \multirow[t]{2}{*}{ education } & $\mathrm{R}$ & $1.85 \%$ & $0.64 \%$ & $\begin{array}{c}4.17 \\
\% \\
\end{array}$ & $\begin{array}{c}0.00 \\
\%\end{array}$ & $\begin{array}{c}29.93 \\
\% \\
\end{array}$ & $1.24 \%$ & $\begin{array}{c}5.61 \\
\% \\
\end{array}$ & $\begin{array}{c}2.70 \\
\% \\
\end{array}$ & $\begin{array}{c}1.48 \\
\% \\
\end{array}$ \\
\hline & $\mathrm{F}$ & $0.00 \%$ & $0.80 \%$ & $\begin{array}{c}1.30 \\
\%\end{array}$ & $\begin{array}{c}0.84 \\
\%\end{array}$ & $\begin{array}{c}17.89 \\
\%\end{array}$ & $5.60 \%$ & $\begin{array}{c}4.00 \\
\%\end{array}$ & $\begin{array}{c}4.26 \\
\%\end{array}$ & $\begin{array}{c}1.37 \\
\%\end{array}$ \\
\hline \multirow{2}{*}{$\begin{array}{c}\text { film and } \\
\text { television } \\
\text { entertainmen } \\
t\end{array}$} & $\mathrm{R}$ & $41.36 \%$ & $3.82 \%$ & $\begin{array}{c}4.17 \\
\%\end{array}$ & $\begin{array}{c}30.72 \\
\%\end{array}$ & $\begin{array}{c}24.82 \\
\%\end{array}$ & $\begin{array}{c}14.29 \\
\%\end{array}$ & $\begin{array}{c}8.67 \\
\%\end{array}$ & $\begin{array}{c}26.35 \\
\%\end{array}$ & $\begin{array}{c}22.96 \\
\%\end{array}$ \\
\hline & $\mathrm{F}$ & $36.00 \%$ & $2.80 \%$ & $\begin{array}{c}11.74 \\
\%\end{array}$ & $\begin{array}{c}21.76 \\
\%\end{array}$ & $\begin{array}{c}25.61 \\
\%\end{array}$ & $4.00 \%$ & $\begin{array}{c}7.60 \\
\%\end{array}$ & $\begin{array}{c}38.30 \\
\%\end{array}$ & $\begin{array}{c}15.98 \\
\%\end{array}$ \\
\hline \multirow[t]{2}{*}{ food/car } & $\mathrm{R}$ & $0.62 \%$ & $0.64 \%$ & $\begin{array}{c}26.39 \\
\%\end{array}$ & $\begin{array}{c}18.95 \\
\%\end{array}$ & $\begin{array}{c}3.65 \\
\%\end{array}$ & $3.11 \%$ & $\begin{array}{c}0.51 \\
\%\end{array}$ & $\begin{array}{c}0.00 \\
\%\end{array}$ & $\begin{array}{c}0.00 \\
\%\end{array}$ \\
\hline & $\mathrm{F}$ & $0.00 \%$ & $0.00 \%$ & $\begin{array}{c}21.74 \\
\%\end{array}$ & $\begin{array}{c}10.04 \\
\%\end{array}$ & $\begin{array}{c}3.25 \\
\%\end{array}$ & $1.20 \%$ & $\begin{array}{c}0.40 \\
\%\end{array}$ & $\begin{array}{c}0.85 \\
\%\end{array}$ & $\begin{array}{c}0.46 \\
\%\end{array}$ \\
\hline \multirow{2}{*}{$\begin{array}{c}\text { culture/popul } \\
\text { ar science } \\
\text { and life }\end{array}$} & $\mathrm{R}$ & $1.23 \%$ & $\begin{array}{c}56.05 \\
\%\end{array}$ & $\begin{array}{c}12.50 \\
\%\end{array}$ & $\begin{array}{c}19.61 \\
\%\end{array}$ & $\begin{array}{c}6.57 \\
\%\end{array}$ & $\begin{array}{c}19.25 \\
\%\end{array}$ & $\begin{array}{c}43.88 \\
\%\end{array}$ & $\begin{array}{c}10.14 \\
\%\end{array}$ & $\begin{array}{c}34.81 \\
\%\end{array}$ \\
\hline & $\mathrm{F}$ & $0.00 \%$ & $\begin{array}{c}51.20 \\
\%\end{array}$ & $\begin{array}{c}8.70 \\
\%\end{array}$ & $\begin{array}{c}23.43 \\
\%\end{array}$ & $\begin{array}{c}10.16 \\
\%\end{array}$ & $\begin{array}{c}28.00 \\
\%\end{array}$ & $\begin{array}{c}45.60 \\
\%\end{array}$ & $\begin{array}{c}8.09 \\
\%\end{array}$ & $\begin{array}{c}29.68 \\
\%\end{array}$ \\
\hline \multirow[t]{2}{*}{ life. } & $\mathrm{R}$ & $11.73 \%$ & $5.73 \%$ & $\begin{array}{c}12.50 \\
\% \\
\end{array}$ & $\begin{array}{c}4.58 \\
\% \\
\end{array}$ & $\begin{array}{c}8.76 \\
\% \\
\end{array}$ & $\begin{array}{c}29.19 \\
\% \\
\end{array}$ & $\begin{array}{c}21.94 \\
\% \\
\end{array}$ & $\begin{array}{c}8.78 \\
\% \\
\end{array}$ & $\begin{array}{c}11.11 \\
\%\end{array}$ \\
\hline & $\mathrm{F}$ & $12.00 \%$ & $\begin{array}{c}10.00 \\
\%\end{array}$ & $\begin{array}{c}18.26 \\
\%\end{array}$ & $\begin{array}{c}8.37 \\
\%\end{array}$ & $\begin{array}{c}10.98 \\
\%\end{array}$ & $\begin{array}{c}16.40 \\
\%\end{array}$ & $\begin{array}{c}12.40 \\
\%\end{array}$ & $\begin{array}{c}9.79 \\
\%\end{array}$ & $\begin{array}{c}10.96 \\
\%\end{array}$ \\
\hline
\end{tabular}

(Note: $\mathrm{R}$ stands for recommended content and $\mathrm{F}$ stands for free reading content)

Taking participant $\mathrm{A}$ as an example, on the first day of her recording, 12 news items are read and 8 are related to film and television entertainment. The next day 12 of the first 25 items recommended by the Headlines Today belong to the film and television entertainment category. During the 10-day experiment, participant A has read a total of 67 movies and entertainment news items, accounting for 41.36 percent of the whole. Considering her reading preference, the aggregator has drawn her reading interests map. Hence, up to 36 per cent of the content recommended goes to the film and television entertainment category, highlighting the personalised principle. Such correlation has also been supported by several other participants. It is worth noting that participant $\mathrm{F}$ did not browse cultural/popular science information on the tenth day, which is the last day of the reading experiment, but 10 of the first 25 items recommended by the aggregator the next day still belong to this category. This shows the cumulative collection of users' reading behaviour by the algorithm recommendation mechanism. The user has read this kind of content every day for the previous nine days, totalling 31 items, so even if the user does not read this kind of news for a short time, the algorithm recommendation mechanism will still recommend the related content according to the users' interest map.

As shown in Table IV, in the fixed reading group, the same holds it true. All the categories read by participants are recommended by the aggregator. The results of the two groups answers the first research question that there is positive correlation between users' reading behaviour and the algorithm recommendation mechanism.

Table IV. The proportion of reading and recommended categories of the control reading group

\begin{tabular}{|c|c|c|c|c|c|c|}
\hline $\begin{array}{c}\text { Participants } \\
\text { Category }\end{array}$ & & J & K & $L$ & $M$ & $N$ \\
\hline \multirow[t]{2}{*}{ sports/health } & $\mathrm{R}$ & $0.00 \%$ & $0.00 \%$ & $\begin{array}{c}0.00 \\
\%\end{array}$ & $\begin{array}{c}0.00 \\
\%\end{array}$ & $\begin{array}{c}0.00 \\
\%\end{array}$ \\
\hline & $\mathrm{F}$ & $0.80 \%$ & $1.60 \%$ & $\begin{array}{c}0.40 \\
\%\end{array}$ & $\begin{array}{c}0.00 \\
\%\end{array}$ & $\begin{array}{c}0.87 \\
\%\end{array}$ \\
\hline \multirow{2}{*}{$\begin{array}{c}\text { finance/scien } \\
\text { ce and } \\
\text { technology }\end{array}$} & $\mathrm{R}$ & $0.00 \%$ & $0.00 \%$ & $\begin{array}{c}0.00 \\
\%\end{array}$ & $\begin{array}{c}0.00 \\
\%\end{array}$ & $100 \%$ \\
\hline & $\mathrm{F}$ & $6.40 \%$ & $2.40 \%$ & $\begin{array}{c}2.40 \\
\%\end{array}$ & $\begin{array}{c}2.40 \\
\%\end{array}$ & $\begin{array}{c}70.13 \\
\% \\
\end{array}$ \\
\hline affairs/social & $\mathrm{R}$ & $0.00 \%$ & $0.00 \%$ & $\begin{array}{c}0.00 \\
\% \\
\end{array}$ & $\begin{array}{c}0.00 \\
\%\end{array}$ & $\begin{array}{c}0.00 \\
\% \\
\end{array}$ \\
\hline
\end{tabular}

ISSN: 0010-8189

(C) CONVERTER 2020

www.converter-magazine.info 


\begin{tabular}{|c|c|c|c|c|c|c|}
\hline news & $\mathrm{F}$ & $38.40 \%$ & $6.40 \%$ & $\begin{array}{c}7.20 \\
\%\end{array}$ & $\begin{array}{c}17.20 \\
\%\end{array}$ & $\begin{array}{c}10.82 \\
\%\end{array}$ \\
\hline \multirow[t]{2}{*}{ education } & $\mathrm{R}$ & $0.00 \%$ & $0.00 \%$ & $\begin{array}{c}0.00 \\
\%\end{array}$ & $100 \%$ & $\begin{array}{c}0.00 \\
\%\end{array}$ \\
\hline & $\mathrm{F}$ & $0.80 \%$ & $0.00 \%$ & $\begin{array}{c}1.20 \\
\%\end{array}$ & $\begin{array}{c}74.80 \\
\%\end{array}$ & $\begin{array}{c}1.73 \\
\%\end{array}$ \\
\hline \multirow{2}{*}{$\begin{array}{c}\text { film and } \\
\text { television } \\
\text { entertainmen } \\
t \\
\end{array}$} & $\mathrm{R}$ & $0.00 \%$ & $100 \%$ & $\begin{array}{c}0.00 \\
\%\end{array}$ & $\begin{array}{c}0.00 \\
\%\end{array}$ & $\begin{array}{c}0.00 \\
\%\end{array}$ \\
\hline & $\mathrm{F}$ & $7.20 \%$ & $\begin{array}{c}78.00 \\
\%\end{array}$ & $\begin{array}{c}7.20 \\
\%\end{array}$ & $\begin{array}{c}0.40 \\
\%\end{array}$ & $\begin{array}{c}5.63 \\
\%\end{array}$ \\
\hline \multirow[t]{2}{*}{ food/car } & $\mathrm{R}$ & $0.00 \%$ & $0.00 \%$ & $100 \%$ & $\begin{array}{c}0.00 \\
\%\end{array}$ & $\begin{array}{c}0.00 \\
\%\end{array}$ \\
\hline & $\mathrm{F}$ & $0.40 \%$ & $1.20 \%$ & $\begin{array}{c}60.80 \\
\%\end{array}$ & $\begin{array}{c}0.00 \\
\%\end{array}$ & $\begin{array}{c}1.73 \\
\%\end{array}$ \\
\hline \multirow{2}{*}{$\begin{array}{c}\text { culture/popul } \\
\text { ar science } \\
\text { and life }\end{array}$} & $\mathrm{R}$ & $100 \%$ & $0.00 \%$ & $\begin{array}{c}0.00 \\
\%\end{array}$ & $\begin{array}{c}0.00 \\
\%\end{array}$ & $\begin{array}{c}0.00 \\
\%\end{array}$ \\
\hline & $\mathrm{F}$ & $42.40 \%$ & $0.03 \%$ & $\begin{array}{c}11.20 \\
\%\end{array}$ & $\begin{array}{c}2.00 \\
\%\end{array}$ & $\begin{array}{c}2.16 \\
\%\end{array}$ \\
\hline \multirow[t]{2}{*}{ life. } & $\mathrm{R}$ & $0.00 \%$ & $0.00 \%$ & $\begin{array}{c}0.00 \\
\% \\
\end{array}$ & $\begin{array}{c}0.00 \\
\% \\
\end{array}$ & $\begin{array}{c}0.00 \\
\%\end{array}$ \\
\hline & $\mathrm{F}$ & $3.20 \%$ & $7.60 \%$ & $\begin{array}{c}9.60 \\
\%\end{array}$ & $\begin{array}{c}3.20 \\
\%\end{array}$ & $\begin{array}{c}6.93 \\
\%\end{array}$ \\
\hline
\end{tabular}

(Note: $\mathrm{R}$ stands for recommended content and $\mathrm{F}$ stands for fixed reading content)

4.2 Personalized recommender system triggers the filter bubbles effect

All the experimental data were coded and calculated thoroughly, and the recommended Pielou index of the 9 participants of the free reading group was obtained. It can be seen from Figure 1 that the average value of the recommended Pielou index of the free reading group shows an obvious fluctuating downward trend, from 0.715 on the first day to 0.624 on the tenth day, and dropped to 0.622 on the ninth day, the bottom figure. Such trend shows that the personalised recommendation mechanism leads to the narrowing of content categories. Further study of the nine individual recommended Pielou index of the free reading group, if taking the recommended Pielou index of the first day as the reference point, it can be seen that the Pielou indexes of the nine participants during the experiment are almost below this figure, that is, the Pielou index of algorithmic recommended content for each participant is also decreasing. Then all the data shows the decline of the diversity of recommended content on the aggregator, confirming the filter bubbles effect.

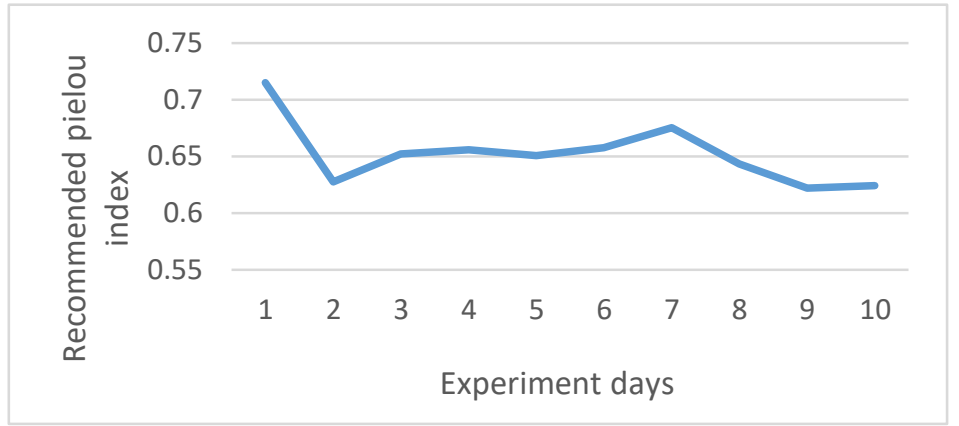

Fig 1. Line chart of the Pielou index mean change of the free reading group

According to the observation of the 5 participants of the control reading group, in that the 5 participants can only read a certain type of content every day (see Table II), their Pielou index has dropped to the lowest level of -0.143 , and accordingly the Pielou index has dropped significantly (see Table V). Compared with the free reading group, the recommended content received by the control group has shown a more significant narrowing effect, and the

ISSN: 0010-8189

(C) CONVERTER 2020 
filter bubbles effect caused by the algorithm recommendation mechanism is also more obvious.

The experimental data shows that based on users' reading interest, no matter how diversified the users choose to read, the algorithm recommendation mechanism leads to the decrease of the content diversity of users' received news in different degrees. So, the answer to research Question 2 has been located, that is the aggregator's algorithm recommendation mechanism causes the decrease of content diversity and leads to the filter bubbles effect.

Table V. Pielou index of reading and recommendation of the control reading group

\begin{tabular}{|c|c|c|c|c|c|c|c|c|c|c|c|}
\hline $\begin{array}{c}\text { Test days } \\
\text { participants }\end{array}$ & & Day 1 & Day 2 & Day 3 & Day 4 & Day 5 & Day 6 & Day 7 & Day 8 & Day 9 & $\begin{array}{l}\text { Day } \\
10\end{array}$ \\
\hline \multirow[t]{2}{*}{$\mathrm{J}$} & $\mathrm{R}$ & 0.698 & 0.764 & 0.596 & 0.550 & 0.596 & 0.355 & 0.545 & 0.472 & 0.358 & 0.439 \\
\hline & $\mathrm{F}$ & $\begin{array}{c}-0.14 \\
3\end{array}$ & $\begin{array}{c}-0.14 \\
3\end{array}$ & $\begin{array}{c}-0.14 \\
3\end{array}$ & $\begin{array}{c}-0.14 \\
3\end{array}$ & $\begin{array}{c}-0.14 \\
3\end{array}$ & $\begin{array}{c}-0.14 \\
3\end{array}$ & $\begin{array}{c}-0.14 \\
3\end{array}$ & $\begin{array}{c}-0.14 \\
3\end{array}$ & $\begin{array}{c}-0.14 \\
3\end{array}$ & $\begin{array}{c}-0.14 \\
3\end{array}$ \\
\hline \multirow[t]{2}{*}{ K } & $\mathrm{R}$ & 0.793 & 0.314 & 0.322 & 0.249 & 0.252 & 0.029 & $\begin{array}{c}-0.14 \\
3\end{array}$ & 0.249 & 0.183 & 0.106 \\
\hline & $\mathrm{F}$ & $\begin{array}{c}-0.14 \\
3 \\
\end{array}$ & $\begin{array}{c}-0.14 \\
3 \\
\end{array}$ & $\begin{array}{c}-0.14 \\
3 \\
\end{array}$ & $\begin{array}{c}-0.14 \\
3 \\
\end{array}$ & $\begin{array}{c}-0.14 \\
3 \\
\end{array}$ & $\begin{array}{c}-0.14 \\
3 \\
\end{array}$ & $\begin{array}{c}-0.14 \\
3 \\
\end{array}$ & $\begin{array}{c}-0.14 \\
3 \\
\end{array}$ & $\begin{array}{c}-0.14 \\
3 \\
\end{array}$ & $\begin{array}{c}-0.14 \\
3 \\
\end{array}$ \\
\hline & $\mathrm{R}$ & 0.673 & 0.717 & 0.322 & 0.025 & 0.183 & 0.029 & 0.106 & $\begin{array}{c}-0.05 \\
5 \\
\end{array}$ & 0.256 & 0.029 \\
\hline & $\bar{F}$ & $\begin{array}{c}-0.14 \\
3 \\
\end{array}$ & $\begin{array}{c}-0.14 \\
3 \\
\end{array}$ & $\begin{array}{c}-0.14 \\
3 \\
\end{array}$ & $\begin{array}{c}-0.14 \\
3\end{array}$ & $\begin{array}{c}-0.14 \\
3\end{array}$ & $\begin{array}{c}-0.14 \\
3 \\
\end{array}$ & $\begin{array}{c}-0.14 \\
3 \\
\end{array}$ & $\begin{array}{c}-0.14 \\
3 \\
\end{array}$ & $\begin{array}{c}-0.14 \\
3 \\
\end{array}$ & $\begin{array}{c}-0.14 \\
3 \\
\end{array}$ \\
\hline \multirow[t]{2}{*}{$M$} & $\mathrm{R}$ & 0.314 & 0.512 & 0.490 & 0.508 & 0.025 & 0.175 & 0.164 & 0.223 & 0.183 & 0.029 \\
\hline & $\mathrm{F}$ & $\begin{array}{c}-0.14 \\
3 \\
\end{array}$ & $\begin{array}{c}-0.14 \\
3 \\
\end{array}$ & $\begin{array}{c}-0.14 \\
3 \\
\end{array}$ & $\begin{array}{c}-0.14 \\
3 \\
\end{array}$ & $\begin{array}{c}-0.14 \\
3 \\
\end{array}$ & $\begin{array}{c}-0.14 \\
3 \\
\end{array}$ & $\begin{array}{c}-0.14 \\
3 \\
\end{array}$ & $\begin{array}{c}-0.14 \\
3 \\
\end{array}$ & $\begin{array}{c}-0.14 \\
3 \\
\end{array}$ & $\begin{array}{c}-0.14 \\
3 \\
\end{array}$ \\
\hline \multirow[t]{2}{*}{$\mathrm{N}$} & $\mathrm{R}$ & 0.764 & 0.629 & 0.714 & 0.245 & 0.238 & 0.179 & 0.099 & 0.256 & 0.245 & 0.175 \\
\hline & $F$ & $\begin{array}{c}-0.14 \\
3 \\
\end{array}$ & $\begin{array}{c}-0.14 \\
3 \\
\end{array}$ & $\begin{array}{c}-0.14 \\
3 \\
\end{array}$ & $\begin{array}{c}-0.14 \\
3 \\
\end{array}$ & $\begin{array}{c}-0.14 \\
3 \\
\end{array}$ & $\begin{array}{c}-0.14 \\
3 \\
\end{array}$ & $\begin{array}{c}-0.14 \\
3 \\
\end{array}$ & $\begin{array}{c}-0.14 \\
3 \\
\end{array}$ & $\begin{array}{c}-0.14 \\
3 \\
\end{array}$ & $\begin{array}{c}-0.14 \\
3 \\
\end{array}$ \\
\hline
\end{tabular}

(Note: $\mathrm{R}$ stands for recommended content and F stands for fixed reading content)

\subsection{Users' reading preference directly impacts the filter bubbles effects}

Because of the existence of algorithmic black box, users don't know what factors drive the recommendation results, and even directly lead to the filter bubbles effect. However, through this experiment, it is found that if individuals can take the initiatives to obtain various news, they can significantly eliminate the negative filter bubbles effect.

The proportion of recommended content diversity of Participant $\mathrm{C}$ is the most balanced one, and all the eight categories are involved and distributed evenly. The cause of this phenomenon can be found out from the changing trend of the Pielou index. Her reading balance index of the first day is 0.3651 , and the last day is 0.6416 (see Table VI). During the 10 days the reading Pielou index generally shows a fluctuating upward trend, indicating that the user pays more attention to the diversity of content when seeking news.

Table VI. Pielou index of reading and recommendation of the free reading group

\begin{tabular}{|c|c|c|c|c|c|c|c|c|c|c|c|}
\hline $\begin{array}{c}\text { Test days } \\
\text { participants }\end{array}$ & & Day 1 & Day 2 & Day 3 & Day 4 & Day 5 & Day 6 & Day 7 & Day 8 & $\begin{array}{c}\text { Day 9 } \\
\text { Day } \\
10\end{array}$ \\
\hline A & $\mathrm{R}$ & 0.647 & 0.724 & 0.526 & 0.618 & 0.662 & 0.643 & 0.779 & 0.753 & 0.600 & 0.709 \\
\cline { 2 - 12 } & $\mathrm{F}$ & 0.443 & 0.557 & 0.527 & 0.457 & 0.699 & 0.688 & 0.654 & 0.650 & 0.792 & 0.670 \\
\hline $\mathrm{B}$ & $\mathrm{R}$ & 0.578 & 0.585 & 0.413 & 0.523 & 0.494 & 0.483 & 0.658 & 0.534 & 0.636 & 0.607 \\
\hline
\end{tabular}




\begin{tabular}{|c|c|c|c|c|c|c|c|c|c|c|c|}
\hline & F & 0.726 & 0.579 & 0.528 & 0.506 & 0.457 & 0.605 & 0.174 & 0.243 & 0.640 & 0.609 \\
\hline \multirow{2}{*}{ C } & R & 0.689 & 0.766 & 0.746 & 0.722 & 0.744 & 0.719 & 0.724 & 0.619 & 0.763 & 0.813 \\
\cline { 2 - 11 } & F & 0.365 & 0.732 & 0.619 & 0.714 & 0.643 & 0.370 & 0.714 & 0.697 & 0.790 & 0.642 \\
\hline \multirow{3}{*}{ D } & R & 0.797 & 0.630 & 0.680 & 0.703 & 0.764 & 0.714 & 0.669 & 0.767 & 0.750 & 0.642 \\
\cline { 2 - 12 } & F & 0.634 & 0.545 & 0.578 & 0.762 & 0.721 & 0.767 & 0.812 & 0.686 & 0.545 & 0.223 \\
\hline \multirow{2}{*}{ E } & R & 0.730 & 0.639 & 0.795 & 0.771 & 0.746 & 0.804 & 0.761 & 0.746 & 0.643 & 0.673 \\
\cline { 2 - 11 } & F & 0.634 & 0.545 & 0.578 & 0.762 & 0.721 & 0.767 & 0.812 & 0.686 & 0.545 & 0.223 \\
\hline \multirow{2}{*}{ F } & R & 0.746 & 0.654 & 0.735 & 0.724 & 0.600 & 0.618 & 0.702 & 0.717 & 0.636 & 0.548 \\
\cline { 2 - 11 } & F & 0.732 & 0.560 & 0.649 & 0.592 & 0.719 & 0.794 & 0.725 & 0.744 & 0.732 & 0.402 \\
\hline \multirow{2}{*}{ G } & R & 0.782 & 0.459 & 0.596 & 0.709 & 0.534 & 0.563 & 0.468 & 0.303 & 0.318 & 0.387 \\
& & & & 0 & & & & & & & \\
\cline { 2 - 11 } & F & 0.771 & 0.599 & 0.768 & 0.726 & 0.563 & 0.594 & 0.600 & 0.482 & 0.509 & 0.509 \\
\hline \multirow{2}{*}{ H } & R & 0.728 & 0.541 & 0.687 & 0.424 & 0.665 & 0.592 & 0.587 & 0.592 & 0.726 & 0.753 \\
\cline { 2 - 11 } & F & 0.429 & 0.497 & 0.545 & 0.379 & 0.506 & 0.732 & 0.700 & 0.725 & 0.335 & 0.725 \\
\hline \multirow{2}{*}{ I } & R & 0.739 & 0.651 & 0.690 & 0.708 & 0.648 & 0.783 & 0.731 & 0.760 & 0.526 & 0.486 \\
\cline { 2 - 10 } & F & 0.436 & 0.777 & 0.837 & 0.655 & 0.429 & 0.711 & 0.654 & 0.711 & 0.520 & 0.497 \\
\hline
\end{tabular}

(Note: R stands for recommended content and F stands for free reading content)

Data of the control group shows that the diversity of news recommended by the aggregator is closely related to users' actively seeking for high-quality contents. Belonging to the low reading balance index, Participant $\mathrm{J}$ chose to read cultural information regularly and within 10 days finished 180 items of cultural information. Her recommended Pielou balance index (0.537) was the highest among the 5 participants (see Table VI). The other two recommended Pielou equilibrium indexes with low figures are participant $\mathrm{K}$ (reading movies and entertainment content) and participant L (reading food content).

The influence of echo chamber on the well-educated elites and the general public is different, that the latter is more likely to blindly follow and lose self-independent thinking. The above data also provides answer to research Question 3, that is, to a certain extent, users can alleviate their excessive involvement in the filter bubbles of algorithm recommendation by actively reading diversified and high-quality information.

\section{Conclusion and discussion}

The latest research shows that although 67 per cent of the respondents report that they have recognized the existence of algorithm recommendation mechanism when reading daily news on aggregators, they do not understand the rules of algorithm recommendation [45]. This research analyses the causal logic of algorithm recommendation, and for the first time, instead of simply relying on users' self-report, employs the Pielou index to measure the distribution of news contents to provide empirical evidence to indicate whether the algorithm recommendation mechanism may leas to the filter bubbles. Moreover, this research takes Headlines Today as the research object, with the hope to aid users better understand the realisation of tailored news and how their reading behaviour affect the algorithm recommendation. The conclusion also reinforces that users should enhance their information literacy in the era of artificial intelligence and big data, make rational use of the algorithm recommendation mechanism, and pay close attention to the diversity of information sources, so as to avoid information bias.

The content distributed by algorithm recommendation mechanism often conceals the influence exerted by the hidden power structure through technology neutrality or external objectivity. This research helps the information flow platform to reflect on the shortcomings of the algorithm mechanism and optimize its strengths while avoiding negative effects. At present, the algorithmic distribution filters the information content by operating the established code and algorithm model. When modelling the user's unique interest map, it is mainly based on the user's background information, reading, "Like" and other data. In view of this, this study proposes that in the ISSN: 0010-8189

(C) CONVERTER 2020 
optimisation of the algorithm recommendation mechanism, the positive guidance to users should also be emphasized, and indicators such as the content influence and the mainstream media recommendation can be added to form a multi-index recommendation system. In addition to meeting the explicit needs of users' news consumption, users' implicit needs should be explored to provide opportunities and possibilities to contact more valuable information. Special focus should be given to the diversity and quality of content in the information pool to avoid the filter bubbles effect through combining the dual advantages of manual intervention and algorithmic filtering.

In the future research we can further expand the scale of participants as well as the content diversity and duration of sample collection. Besides measuring users' basic reading behavior data, we can also add other reference data such as users' characteristics, surfing time, shares or "Like" into the calculating process so to carry out more accurate and scientific evaluation.

\section{References}

[1] J. Z. Zhang, (2017). Light in the Darkness: Interpretation of 2017 Oxford Reuters Digital News Report. Journalism and Mass Communication Monthly, (10), 95-102.

[2] Q. H, Analysis of the Chinese Netizens' Behaviors 2017, Retrieved February 2020 from https://www.analysys.cn/article/analysis/detail/1000785/.

[3] Pasquale, Frank. (2015). The Black Box Society: The Secret Algorithms That Control Money and Information. Cambridge, MA: Harvard University Press.

[4] Eli. Pariser, (2011). The Filter Bubble: What the Internet Is Hiding from You.New York, NY: Penguin Press.

[5] Y. S. Xia, (2017). On the development strategy of Headlines Today--- from the perspective of McLuhan's media technology theory. Journal of News Research, 8(02), 81.

[6] B. C. Xu, (2017). Five major changes in news client communication-taking a little information and Headlines Today as examples. Media, (05), 47-49.

[7] Y. B. Cai, (2014). Interpretation of the Competitive Advantage and Communication of Today's Headline. Young Journalist, (29), 69.

[8] J. C. Wang, J. N. Chu, (2014). Headlines Today innovation and its enlightenment to traditional media. Young Reporters, (24), 96-97.

[9] Q. K. Zhang, J. Meng, (2014). Analysis of Infringement Identification of Search News Aggregation APP. Intellectual Property, (07). 29-33+67.

[10] B. Wang, W. Z. Li, (2018). How to puncture the narrowing of cognition and its avoidance in pushing news by filter bubbles algorithm. News and Writing, (09), 20-26.

[11] Y. Z. Wei, J. Wang (2014). Viewing the rights protection of news media from the Headlines Today incident. Journalist, (07), 40-44.

[12] G. M. Yu, (2014). Integrated economy: the innovation of business model needs the innovation of profit model to guarantee---Some views on the copyright dispute caused by Headlines Today. News and Writing, (08), 44-45.

[13] S. S. Mei, (2016). Analysis on the headline news of the network aggregation news client---Taking Headlines Today as an example. Western Radio and Television, (16), 25+35.

[14] S. S. Zhao, (2017). The reasons and countermeasures of "information cocoon room" caused by personalized recommendation of news clients. Western Radio and Television, (24), 10-11.

[15] Q. H. Shao, (2017). The subversion and re-creation of traditional media news production by mobile aggregation new media---Taking the news production mode of Headlines Today as an example. Journalism Lover, (01), 37-40.

[16] Y. Q. Zhou, J. W. Hu, (2018). Multidimensional Ponderation of News under the Algorithmic Distribution. New Media and Society, (03), 14-23.

[17] J. G. Liu, T. Zhou, Q. Guo, B. H. Wang, (2009). Review of evaluation methods of personalized recommendation system. Complex Systems and Complexity Science, 6(03), 1-10.

ISSN: 0010-8189

(C) CONVERTER 2020

www.converter-magazine.info 
[18] L. Liu, X. L. Ren, (2008). Research progress and prospect of recommendation system. Journal of Information Systems, (01), 82-90.

[19] X. Guo, H. P. Liu, (2012). Summary of Personalized Recommendation System. Computer Engineering and Application, 48(07), 66-76.

[20] Z. J. Li, Q. H. Zhou, Q. H. Shuai, (2009). A recommendation system model based on isomorphism and integration of content and collaborative filtering. Computer Science, 36(12), 142-145.

[21] Hu Jiangwei, Zhou Yunqian. (2020). Technical ethics conflict and its regulation of news algorithm distribution. Young Reporter, (03), 29-30.

[22] Liu Qinghua. (2007). Personalized recommendation technology and its application in e-commerce. Nanchang: Nanchang University.

[23] Zeng Ziming, Chen Beibei. (2015). Research on Personalized Reading Recommendation Based on Context Awareness in Mobile Environment. Information Theory and Practice, 38(12), 31-36.

[24] Mou Zhijia, Wu Fati. (2015). Research on Personalized Learning Resources Recommendation Based on Learner Model in E-schoolbags. Research on Audio-visual Education, 36(01), 69-76.

[25] Sha Jing, Zeng Gong Li, Yang Yang. (2020).Personalized Game Recommendation Method Based on Implicit Feedback. Journal of System Simulation, doi:10.16182/j.issn1004731x.joss.19-0636.

[26] Jiang Hong, Lu Man. (2017). Rebuilding "Media": News “Algorithm” in Actor Network. Journalist, (04), 26-32.

[27] Zhao Shuangge, Yue Mengyi. (2018). "Quantitative transformation” of news: the challenge and response of algorithm recommendation to media ethics. Contemporary Communication, (04), 52-56.

[28] Zhang Zhi. (2019). Thoughts on algorithmic journalism ethics in news production in the era of intellectual media. Journal of Hainan University (Humanities and Social Sciences Edition), 37(02), 70-78.

[29] Hu Shuguang, Chen Changfeng. (2019). Concept and Norm: Media Ethical Dilemma and Its Guidance in the Age of Artificial Intelligence. China Publishing, (02), 11-15.

[30] Hu Yang, Chen Jianmei. (2020). Deep hybrid collaborative filtering recommendation algorithm for complete cold start. Computer and Digital Engineering, 48(03), 540-545.

[31] Yang Liming. (2020). Application, Influence and Reflection of Personalized Recommendation in Mobile News Communication. News and Communication Review, 73(02), 47-58.

[32] Guo Henan, He Qian. (2020). Deconstruction and reconstruction of Chinese news values from the perspective of algorithm recommendation. Journal of Southwest Minzu University (Humanities and Social Sciences Edition), 41(06), 150-156.

[33] Wang Xi. (2017). Open the "black box" of algorithm distribution---Quantitative research based on Headlines Today news push. Journalist, (09), 7-14.

[34] Xu Di. (2019). Polysemy and escape in algorithm practice: taking news recommendation algorithm as an example. Journalism University, (12), 39-49+120.

[35] Fang Shishi. (2018). How the algorithm reshapes journalism: status quo, problems and regulations. News and Writing, (09), 11-19.

[36] Guo Xiaoan, Gan Xinyue. (2018). "Poke off your bubbles"---the formation and elimination of "filtering bubbles" in the era of algorithm recommendation. Journal of Global Media Science, 5(02), 76-90.

[37] Chen Changfeng, Shi Wen. (2018). Technical Interpretation and Value Discussion of Personalized News Recommendation Algorithm. Chinese Editorials, (10), 9-14.

[38] Zhang Aijun, Wang Shouhang. (2020). Algorithm: A New Power Form. Research on Governance Modernization, 36(01), 39-45.

[39] Resnick P, Garrett R K, Kriplean T, et al. (2013). Bursting your (filter) bubble: strategies for promoting diverse exposure. In proceedings of the 2013 conference on computer supported cooperative work cooperation. (pp. 95-100).

[40] Nguyen,T.T.,Hui,P.M.,Harper,F.M.,Terveen,L.,\&Konstan,J.A.(2014, April).Exploring the filter bubble:the effect of using recommender systems on content diversity. in proceedings of the 23rd international conference on the world wide web (pp.677-686) .

ISSN: 0010-8189

(C) CONVERTER 2020 
[41] Bechmann A, Nielbo K L. (2018). Are We Exposed to the Same"News"in the News Feed? An empirical analysis of filter bubbles as information similarity for Danish Facebook users. Digital Journalism, 6(8), 990-1002.

[42] Haim M, Graefe A, Brosius H B. (2018). Burst of the filter bubble? Effects of personalization on the diversity of Google News. Digital Journalism, 6 (3), 330-343.

[43] Judith Möller, Damian Trilling. (2018). Do not blame it on the algorithm--- an empirical assessment of multiple recommender systems and their impact on content diversity. Information, Communication \& Society, 21(7), 959-977.

[44] Zhang Yiming. (2014). Will Machine Replace the Traditional Editors. Intellectual Property, (03), 36-40.

[45] Huang Xinyuan. (2019). A Research on the Attitudes of Individuals towards Recommendation Algorithm: Based on 1075 Users of News Apps Applied Recommendation. Editorial Friend, (06), 63-68. 